\title{
Short-term Quality of Life After Cytoreductive Surgery and Hyperthermic Intraperitoneal Chemotherapy
}

\author{
Özgül Düzgün ${ }^{1}$, İnanç Samil Sarıcl², Serkan Gökçay ${ }^{3}$
}

Introduction: Cytoreductive surgery (CRS) and hyperthermic intraperitoneal chemotherapy (HIPEC) have been increasingly performed in many advanced centers of our country. Short-term quality of life (QoL) after the CRS with HIPEC was investigated in Turkish population. The purpose of our study was to investigate the QoL in patients operated for peritoneal carcinomatosis (PC).

Methods: Retrospectively collected data from 42 consecutive patients, who had undergone CRS and HIPEC, and 92 abdominal malignancy patients after oncological surgery without CRS and HIPEC were selected in the study between 2012 and 2015. A Turkish version of the European Organization for Research and Treatment of Cancer questionnaire (QLQ-C30) was used at the 6th month following surgery for the QoL assessment. Statistical analysis was done with one sample $t$-test, and $p<0.05$ was accepted as statistically significant.

Results: In total, 42 CRS+HIPEC patients were analyzed; of which, 30 (71.4\%) were female and 12 (28.5\%) were male. The median age was 52 years (range, 22-69). CRS with HIPEC was performed for colorectal carcinoma in 15 patients (35.7\%), ovarian cancer in 12 patients (28.5\%), gastric cancer in 6 patients (14.2\%), pseudomixsoma peritonei in 3 patients (7.1\%), sarcoma in 3 patients (7.1\%), and mesenchymal tumor in 3 patients (7.1\%). The median intraoperative peritoneal carcinomatosis index score was 15 (6-29), whereas the completeness of the cytoreductive score was 0 and 1 . The median follow-up period for all patients was 12 months (range, 6-22 months). The functional and symptom scores were equal between the CRS with HIPEC and without CRS+HIPEC cancer patients $(p>0.05)$.

Conclusion: Short-term QoL after the CRS with HIPEC patients and without the CRS+HIPEC oncologic patients is found to be similar in Turkish population.

Keywords: Cytoreductive surgery (CRS), hyperthermic intraperitoneal chemotherapy (HIPEC), Turkish population, quality of life (QoL)

This study was presented $20^{\text {th }}$ National Surgery Congress, 13-17 April 2016, Antalya, Turkey.

${ }^{1}$ Deapartment of Oncological Surgery, Cukurova University School of Medicine, Adana, Türkiye ${ }^{2}$ Department of General Surgery, Health Sciences Unviersity Kanuni Sultan Süleyman Training and Research Hospital, İstanbul, Türkiye ${ }^{3}$ Department of Medical Oncology, Çukurova University School of Medicine, Adana, Türkiye

\section{Address for Correspondence:}

İnanc Șamil Sarıcı

E-mail: issarici2015@gmail.com

Received: 28.03.2017

Accepted: 23.11.2017

(C) Copyright 2018 by Available online at istanbulmedicaljournal.org

\section{Introduction}

Peritoneal carcinomatosis (PC) which is called advanced stage of abdominal cancer continues to be a problem that not fully solved at the present time. Due to both medical cost burdens and inferior treatment results of oncologic diseases with palliative chemo-radiotherapy or supportive care in advance, in 1989 Sugarbaker et al. (1) presented cytoreductive surgery (CRS) and hyperthermic intraperitoneal chemotherapy (HIPEC) as a stunning method for appropriate patients with PC. Initially, this technique had excessive treatment-related morbidity and mortality with a major concern. However, completion of learning curve in the experienced centers resulted an overall decreasein postoperative morbidity and mortality, as shown in the recent studies (2, 3).

Regardless of enhanced survival with admissible morbidity and mortality of surgery, quality of life (QoL) in patients with PC is still controversial. Due to broad resection and possible chemotherapy toxicity, changes in QoL patients with CRS and HIPEC could be more than simple surgery.

These studies were performed in Western and Asian population;nevertheless, have not been applied in Turkish population. Thus, in the present study, we aimed to share out QoL results of our PC patients with CRS and HIPEC with comparison the oncologic patients operated only without CRS and HIPEC.

\section{Methods}

Prospectively collected data of 42 PC patients who had undergone CRS and HIPEC in Department of Surgical Oncology, Çukurova University School of Medicine, between December 2012 and May 2015, were analyzed. Preoperative evaluation was made with thoraco-abdominal computerized tomography (CT) and positron emission tomography (PET)-CT. Patients were chosen as candidates for CRS and HIPEC in multi-disciplinary oncology meeting aiming a complete cytoreduction. For comparison, 92 abdominal malignancy patients after oncological surgery without CRS and HIPEC were selected randomly in our oncology clinic. Ethic Committee approval was approved by the In- 
stitutional Review Board of the Çukurova University for this study (CUM 2015-48-28). Informed consent was obtained from each patient.

Intraoperatively spreading of tumour was evaluated by the PC index (PCI) (4). Residual tumor presence after cytoreduction was reevaluated with residual completeness scoring (CCS) (5). Mitomycin $\mathrm{C}$ and cisplatin were used according to the primary origin of the tumor. Chemotherapeutic drug selection and preparation were done by the clinical oncology experts. After CRS, four intrabdominal drainage cathaters were inserted into the abdomen, and HIPEC was administered for 60 minutes (range, 30-60).

The Turkish form of the European Organization for Research and Treatment of Cancer (EORTC) QLQ-C30 which was confirmed previously by Hoopman et al. (6) was selected for QoL. All questionnaires were administered by clinical oncologists. Functional measurement (physical, role, cognitive, emotional, social), symptom degree (fatigue, pain, dyspnea, loss of appetite, sleeping, diarrhea, constipation, nausea or vomiting, and financial problems), and global health status were measured in all patients. Scoring was ranged between 0 and 100 (7).

\section{Statistical Analysis}

Statistical analyses were performed using SPSS (Statistical Package for Sociel Sciences) 15.0 for Windows (SPSS Inc.; Chicago, IL, USA). The mean QoL scores were calculated in both groups and compared by using one-sample t- test. P values $<0.05$ were considered statistically significant.

\section{Results}

Forty-two patients with CRS and HIPEC with 92 oncologic patients operated without CRS and HIPEC were compared. Of the 42 patients with PC, 30patients (71.4\%) were female and 12 (28.5\%) were male. The median age was 52 years (range, 22-69). No significant difference was observed according to the demographics of the two groups (Table1).

CRS with HIPEC were performed for colorectal carcinoma in 15 patients (35.7\%), ovarian cancer in 12 patients (28.5\%), gastric cancer in 6 patients (14.2\%), pseudomixsoma peritonei in 3 patients (7.1\%), sarcoma in 3 patients (7.1\%), and mesenchymal tumor in 3 patients $(7.1 \%)$. The median intraoperative peritoneal carcinomatosis index ( $\mathrm{PCl}$ ) score was 15 (6-29) while the completeness of cytoreductive score (CCS) was 0 and 1. The median follow-up period for all patients was 12 months (range, 6 - 22). Functional and symptom scores were equal between CRS with HIPEC and without CRS+HIPEC cancer patients ( $p>0.05)$. The ECOG performance status of all patients was 0 or 1 .

Without PC group included colorectal carcinoma in 44 patients (47.8\%), ovarian cancer in 30 patients (32.6\%), gastric carcinoma in 15 patients $(16.3 \%)$, and sarcomas in 3 patients (3.2\%).

The median duration of operation for CRS and HIPEC was 480 minutes (range, 310-565) and that for without CRS and HIPEC group was 110 minutes (range, $80-160)(p<0.001)$. The median PCI was 15 (range, 6-29). There were 39 patients in CCS 0 and 3 patients in CCS 1. The median admission in intensive care unit (ICU) was 1 day (range, 0-12). Median length of hospital stay was 13 days

(range, 7-28).
Table 1. Demographics of patients, comorbidity and the primary tumor

\begin{tabular}{|c|c|c|}
\hline Variables & $\begin{array}{c}\text { CRS+HIPEC } \\
\text { patients } \\
n=42\end{array}$ & $\begin{array}{c}\text { Oncology patients } \\
\text { operated } \\
\text { without CRS+HIPEC } \\
n=92\end{array}$ \\
\hline Gender (M/F) & $42(12 / 30)$ & $92(31 / 61)$ \\
\hline Age (year) & $52(22-69)$ & $58(25-72)$ \\
\hline $\mathrm{BMI}\left(\mathrm{kg} / \mathrm{m}^{2}\right)$ & $21.1 \pm 4.2$ & $22.2 \pm 3.5$ \\
\hline \multicolumn{3}{|l|}{ Education N (\%) } \\
\hline Primary & $4(9.5 \%)$ & $8(8.7 \%)$ \\
\hline High School & $12(28.5 \%)$ & $27(29.3 \%)$ \\
\hline University & $26(62 \%)$ & $52(56.5 \%)$ \\
\hline \multicolumn{3}{|l|}{ Comorbidities $\mathrm{N}$} \\
\hline Hypertension & 12 & 14 \\
\hline Diabetes mellitus & 7 & 17 \\
\hline Asthma & 3 & 5 \\
\hline Cardiovascular disease & 1 & 6 \\
\hline \multicolumn{3}{|l|}{ Primary tumor N (\%) } \\
\hline Colorectal & $15(35.7 \%)$ & $44(47.8 \%)$ \\
\hline Ovarian & $12(28.5 \%)$ & $30(32.6 \%)$ \\
\hline Gastric & $6(14.2 \%)$ & $15(16.3 \%)$ \\
\hline Pseudomyxoma peritonei & $3(7.2 \%)$ & - \\
\hline Sarcoma & $3(7.2 \%)$ & $3(3.2 \%)$ \\
\hline Mesenchimal tumor & $3(7.2 \%)$ & - \\
\hline
\end{tabular}

The EORTC-QLQ-C30 scores of patients after CRS and HIPEC compared with patients without CRS and HIPEC are demonstrated in Table 2. There were no difference between the groups of EORTCQLQ-C30 scores.

\section{Discussion}

CRS and HIPEC enhanced survival of patients with peritoneal dissemination of cancer (1-3). Despite improved survival and admissible morbidity and mortality of the surgery, QoL for the patients undergoing CRS and HIPEC is still controversial. In spite of there have been many articles with respect to QoL scoring calculated for patients with CRS and HIPEC, there is no information about these scores in Turkish PC patients. To our knowledge, this is the first study from a Turkish university hospital referral oncology unit that assesses QoL outcomes who undergone CRS with HIPEC.

There have been recent publications in the literature about EORTC QLQ C-30 to assess the QoL for PC patients. Schmidt et al. (8) evaluated the QoL of patients who underwent CRS combined with HIPEC, and found that QoL is associated with an increased morbidity and mortality according to the difficulty of surgery. On the other hand, in the study of Alves et al. (9) applied EORTC QLQ C-30 questionnaire to their PC patients who undergone CRS with HIPEC. The authors found an improvement in QoL at one year following the procedure. Furthermore, Tan et al. (10) alcompared CRS 
Table 2. Comparison of EORTC QLQ C-30 scoresin patients with CRS and HIPEC and oncology patients operated without CRS and HIPEC

\begin{tabular}{lccc}
$\begin{array}{l}\text { EORTC QLQ-C30 } \\
\text { parameters }\end{array}$ & $\begin{array}{c}\text { CRS+HIPEC patients } \\
(\mathbf{n = 4 2 )}\end{array}$ & $\begin{array}{c}\text { Oncology patients operated } \\
\text { without CRS+HIPEC } \\
(\mathbf{n}=\mathbf{9 2})\end{array}$ & $\mathbf{p}$ \\
\hline Physical functioning & $78(70-87)$ & $84(75-90)$ & 0.524 \\
\hline Role functioning & $81(76-91)$ & $85(79-93)$ & 0.406 \\
\hline Cognitive functioning & $87(81-94)$ & $89(85-96$ & 0.305 \\
\hline Emotional functioning & $82(75-88)$ & $84(73-90)$ & 0.555 \\
\hline Social functioning & $81(75-90)$ & $82(75-90)$ & 0.465 \\
\hline Global quality of life & $65(57-79)$ & $68(55-82)$ & 0.343 \\
\hline Fatigue & $14(10-22)$ & $16(11-25)$ & 0.245 \\
\hline Pain & $15(6-24)$ & $16(7-25)$ & 0.324 \\
\hline Nausea and vomiting & $8(2-15)$ & $9(1-17)$ & 0.405 \\
\hline Dyspnea & $10(3-17)$ & $9(2-17)$ & 0.325 \\
\hline Insomnia & $19(8-28)$ & $17(8-26)$ & 0.308 \\
\hline Appetite loss & $10(2-18)$ & $9(3-17)$ & 0.243 \\
\hline Constipation & $15(6-22)$ & $13(5-21)$ & 0.543 \\
\hline Diarrhea & $9(3-15)$ & $8(2-17)$ & 0.550 \\
\hline Financial problems & $23(11-35)$ & $24(11-37)$ & 0.605 \\
\hline CRS: cytoreductive surgery; HIPEC: hyperthermic intraperitoneal chemotherapy; EORTC QLQ-C30: European Organization for research and treatment of cancer \\
quality of life
\end{tabular}

plus HIPEC patients with their cancer free patients. They found cognitive functioning scores and fatigue scores better in their CRS+HIPEC patients.

In the present study, the Turkish version of EORTC QLQ C-30 was evaluated between PC patients with CRS and HIPEC and patients without CRS and HIPEC, 6 months after surgery, and no significant difference was found between two groups. However, our study have some limitations. First one is its retrospective design. Lack of the patients basic QoL scores for reference values after CRS and HIPEC is the second limitation. Third limitation is the variety of primary cancer origins. Compared to the population of oncology patients operated without CRS and HIPEC in our center, those patients that underwent CRS and HIPEC had smilar scores in global health, physical functioning, emotional functioning and social functioning.

Developing hospital care, advances in ICU for postoperative patient care, and a significant increase in the numbers of specialized oncology units in private sector as well as in the state hospitals can be the reason of no difference of QoL. On the other hand, successful tumor free surgery, lack of serious morbidity, adequate enteral nutrition, achievement of longer disease-free survival and rapid return to normal life of the oncology patients are important factors affecting QoL. This is likely due to the fact that many of the patients after cancer surgery in Turkey starting to take chemotherapy in this period, quick return to their normal economic, social and physical lives that can be explained why scores are better in both CRS and HIPEC and without CRS and HIPEC groups.

\section{Conclusion}

Short term QoL after CRS with HIPEC and oncology patients operated without CRS and HIPEC seems to be equal in our Turkish population.
Ethics Committee Approval: Ethic Committee approval was recieved by the Institutional Review Board of the Çukurova University for this study (CUM 2015-48-28).

Informed Consent: Informed consent was obtained from the patients who participated in this study

Peer-review: Externally peer-reviewed.

Author Contributions: Concept - Ö.D. I.S.S.; Design - I.S.S, Ö.D., S.G.; Supervision I.S.S. .; Resource - Ö.D., S.G. Materials - Ö.D., S.G.; Data Collection and/ or Processing - Ö.D., S.G.; Analysis and/or Interpretation - I.Ș.S., Ö.D.; Literature Search - I.S.S, Ö.D; Writing - I.S.S., Ö.D.; Critical Reviews - I.Ş.S., Ö.D.

Conflict of Interest: The authors have no conflict of interest to declare.

Financial Disclosure: The authors declared that this study has received no financial support.

\section{References}

1. Sugarbaker PH, Cunliffe WJ, Belliveau J, de Bruijn EA, Graves T, Mullins $\mathrm{RE}$, et al. Rationale for integrating early postoperative intraperitoneal chemotherapy into the surgical treatment of gastrointestinal cancer. Semin Oncol 1989; 16: 83-97.

2. Chua TC, Yan TD, Saxena A, Morris DL. Should the treatment of peritoneal carcinomatosis by cytoreductive surgery and hyperthermic intraperitoneal chemotherapy still be regarded as a highly morbid procedure?: a systematic review of morbidity and mortality. Ann Surg 2009; 249: 900-7. [CrossRef]

3. Wilson KA, Dowling AJ, Abdolell M, Tannock IF. Perception of quality of life by patients, partners and treating physicians. Qual Life Res 2000; 9: 1041-52. [CrossRef]

4. Jacquet P, Sugarbaker PH. Current methodologies for clinical assessment of patients with peritoneal carcinomatosis. J Exp Clin Cancer Res 1996; 15: 49-58. 
5. Esquivel J, Elias D, Baratti D, Kusamura S, Deraco M. Consensus statement on the loco regional treatment of colorectal cancer with peritoneal dissemination. J Surg Oncol 2008; 98: 263-7. [CrossRef]

6. Hoopman R, Muller MJ, Terwee CB, Aaronson NK. Translation and validation of the EORTC QLQ-C30 for use among Turkish and Moroccan ethnic minority cancer patients in the Netherlands. Eur J Cancer 2006; 42: 1839-47. [CrossRef]

7. Fayers PM, Aaronson NK, Bjordal K, Curran D, Groenvold M. The EORTC QLQ-C30 Scoring Manual. 2nd Ed., Brussels: In: European Organization for Research and Treatment of Cancer; 1999.

8. Schmidt U, Dahlke MH, Klempnauer J,Schlitt HJ, Piso P. Perioperative morbidity and quality of life in long-term survivors following cytoreductive surgery and hyperthermic intraperitoneal chemotherapy. Eur J Surg Oncol. 2005; 31: 53-8. [CrossRef]
9. Alves S, Mohamed F, Yadegarfar G, Youssef H, Moran BJ. Prospective longitudinal study of quality of life following cytoreductive surgery and intraperitoneal chemotherapy for pseudomyxoma peritonei. Eur J Surg Oncol 2010; 36: 1156-61. [CrossRef]

10. Tan WJ, Wong JF, Chia CS, Tan GH, Soo KC, Teo MC. Quality of life after cytoreductive surgery and hyperthermic intraperitoneal chemotherapy: an Asian perspective. Ann Surg Oncol 2013; 20: 4219-23. [CrossRef]

Cite this article as: Düzgün 0̈, Sarıcı iș, Gökçay S. Short-term Quality of Life after Cytoreductive Surgery and Hyperthermic Intraperitoneal Chemotherapy. İstanbul Med J 2018; 19: 143-6. 